\title{
A Base Epistemológica da Ação Administrativa nas Organizações Substantivas e a Formação do Gestor SOCIAL
}

The Epistemological Basis of Administrative Action in Substantive organizations and the Formation of Social Manager

José Francisco Salm

Doutor em Administração Pública pela Universidade do Sul da Califórnia. Professor do Centro Universitário Internacional - UNINTER. Curitiba, PR, Brasil. E-mail: joséfrancisco.salm@gmail.com

\section{Maria Ester Menegasso}

Doutorado em Engenharia de Produção pela Universidade Federal de Santa Catarina. Professora do Curso de Administração Pública da Universidade do Estado de Santa Catarina - UDESC/CESFI. Florianópolis, SC, Brasil. E-mail: menester@uol.com.br

\section{Resumo}

A base epistemológica da ação administrativa em prática nas organizações substantivas é distinta daquela que ocorre nas organizações burocráticas, conforme se depreende da Teoria da Delimitação dos Sistemas Sociais proposta por Alberto Guerreiro Ramos. A ação administrativa praticada nas organizações burocráticas sustenta-se na racionalidade instrumental, na ética da responsabilidade, na unidimensionalidade do ser humano e nos ditames da esfera privada. A ação administrativa praticada nas organizações substantivas sustenta-se na racionalidade instrumental e substantiva, na ética da responsabilidade e da convicção, na multidimensionalidade humana e nos primados da esfera pública. Neste artigo, pretende-se descobrir se as organizações substantivas realizam seus propósitos por meio de ação administrativa própria, cujo escopo vai além daquela praticada nas organizações burocráticas.

Palavras-chave: Base Epistemológica. Ação Administrativa. Organização Substantiva. Formação do Gestor Social.

\section{Abstract}

The epistemological basis of administrative action in substantive organizations practice is distinct from that which occurs in bureaucratic organizations, as seen from the Theory of Social Systems Delimitation, proposed by Alberto Guerreiro Ramos. The administrative action taken in bureaucratic organizations is sustained by instrumental rationality, responsibility ethics, human one-dimensionality, and dictates of the private sphere. The administrative action taken in substantive organizations is sustained by instrumental and substantive rationality, responsibility and conviction ethics, human multidimensionality, and excelled in the public sphere. Substantive organizations accomplish their purposes through their own administrative action, whose scope goes beyond that practiced in bureaucratic organizations.

Keywords: Epistemological Basis. Administrative Action. Substantive Organization. Social Manager Formation. 


\section{INTRODUÇÃO}

As mudanças que ocorrem na sociedade ocidental desde o final da década de 1960 são responsáveis pelo desenvolvimento de novos arranjos políticos, sociais e econômicos que, no seu conjunto e dada a sua especificidade, não têm precedentes na história. Já no começo da década de 60, em diversos países, deu-se início a um processo de maior participação do cidadão na esfera pública. Essa participação ocorreu, em maior escala, nos grupos poliárquicos (DAHL, 2005), nas associações e na comunidade, entidades que, a partir de então, passaram a ter maior relevo na esfera pública (CALEGARE; SILVA JUNIOR, 2009). Também surgiu um sem-número de organizações sociais, no seu conjunto, denominadas terceiro setor. O mercado, por seu turno, incorporou a ideia da responsabilidade social e teve sua atuação delimitada por meio de algumas poucas restrições, principalmente aquelas relacionadas com a exploração do meio ambiente natural ou biosfera. No âmago dessas e de mercado, da massificação das pessoas em sociedade e dos limites que são postos ao exercício da liberdade dos cidadãos, além das questões ligadas à preservação da natureza e à prática da ética (CATLAW, 2007). Todas essas mudanças e questionamentos tiveram seus reflexos na ação administrativa em prática nas organizações.

A ação administrativa que ocorre no âmbito das organizações formais é uma modalidade de ação social que se consagra pela prática da racionalidade e pela responsabilidade no alcance de objetivos. No contexto das mudanças em curso, a ação administrativa cria corpo porque a sua prática nessas organizações está tanto a serviço da esfera pública, quanto da esfera privada, embora com propósitos distintos. Em uma esfera, ela promove o interesse público; em outra, o interesse privado. Esse fato tem relação direta com os questionamentos que estão no centro das mudanças pelas quais estamos atravessando, haja vista os conflitos de interesses entre essas duas esferas (ARENDT, 2014).

Esses conflitos de interesse ganham vulto à medida que se discute a necessidade de maior eficiência ou racionalidade no uso de recursos e maior responsabilidade na produção de bens e serviços pelo estado (DICKINSON; SULLIVAN, 2014). Na busca da maior eficiência e responsabilidade, surgiram rearranjos nas estruturas, tecnologias e teorias das organizações de na- tureza burocrática, produtoras de bens e serviços. Esses rearranjos ocorreram com mais agilidade nas organizações da esfera privada do que nas da esfera pública, em parte, também, por causa dos encaminhamentos legais que constrangem a velocidade das mudanças nas organizações burocráticas públicas. Como consequência, as organizações burocráticas que prestam serviços na esfera pública não proporcionaram respostas para a sociedade na velocidade em que ela as demandava, fato que abriu espaço para as organizações do terceiro setor. Tal fato também deu oportunidade para que as organizações burocráticas da esfera privada passassem a produzir o bem público em maior escala, mas esse não é o foco da discussão neste momento. É importante destacar que o bem público passou a ser produzido tanto pelas organizações de natureza burocrática, mantidas só pelo poder público, quanto por organizações mais flexíveis e menos burocráticas, mantidas ou não pelo poder público. As primeiras são burocracias públicas, espaço em que se exerce a administração pública (DENHARDT; CATLAW, 2014; MATIAS-PEREIRA, 2010), as segundas são organizações do terceiro setor, espaço em que se exerce a gestão social (CANSADO; SAUSEN; VILLELA, 2013); ambas, porém, realizam as suas ações na esfera pública.

Muitas dessas organizações, que realizam as suas ações na esfera pública, podem ser denominadas organizações substantivas pelo tipo de ação administrativa que nela se pratica, por serem mais flexíveis e menos burocráticas, pela possibilidade objetiva de autorrealização que oferecem aos seus membros e pela singularidade de propósito das pessoas que delas participam, já que, usualmente, elas não estão motivadas apenas pelo ganho econômico imediato (RAMOS, 1981; SERVA, 1997).

É importante esclarecer que essa não é uma concepção heurística de organização substantiva, uma vez que "não se espera de nenhuma situação existente na vida social que coincida com esses tipos ideais. No mundo concreto, só existem sistemas sociais mistos" (RAMOS, 1981). Ademais, de acordo com o que preceitua a "Lei Cíclica da Decadência e da Queda" (VOEGELIN, 1963), uma concepção ideal, seja de sociedade ou de organização, corrompe-se na proporção em que passa a existir. Por via de consequência, uma concepção ideal de organização substantiva também perde, em algum grau, suas características e design à 
medida que se realiza. Logo, pode-se afirmar que na realidade só existem organizações substantivas mistas que se caracterizam como mais flexíveis, menos burocráticas, orientadas, também, pela ética da convicção e outras formas substantivas de vida. Essas formas promovem oportunidades para a autorrealização dos seus participantes e para a consecução de objetivos relacionados ao bem comum. A partir dessas características, algumas organizações não governamentais e outros arranjos comunitários podem ser identificados como organizações substantivas. Esse é o entendimento que se aplica às organizações substantivas neste trabalho. Organizações de economia de comunhão, prática de dádiva, economia solidária, entidades de suporte e entretenimento de idosos e institutos voltados para a ocupação e renda são alguns exemplos de organizações substantivas, quando se conformam às características acima descritas.

Tanto as organizações substantivas quanto as organizações burocráticas públicas, embora vistas por prisma diferente, realizam a ação administrativa com o propósito de produzir o bem comum na esfera pública. Em muitos casos, é importante frisar, a produção do bem comum, entendido aqui como produção dos serviços públicos, resulta da convergência da ação administrativa desses dois tipos de organização. Essa parceria, que também pode incluir a comunidade, vem crescentemente sendo reconhecida pelos meios acadêmicos como coprodução do bem público (SALM, 2014). A coprodução é, portanto, uma importante estratégia para a convergência de esforços entre a administração pública e a gestão social (DENHADRT; DENHARDT, 2012). Essa convergência de esforços, embora muitas vezes não ordenada de forma instrumental, e a ação administrativa que ocorre em cada uma dessas organizações que agem na esfera pública produzindo o bem público, merecem ser ainda mais bem-compreendidas. Mas há necessidade de se dar um foco específico, mais restrito, a essa pretensão, para tornar a compreensão possível. Assim, levando-se em conta essa restrição e o signo das mudanças em curso, resta perguntar que elementos constituem a ação administrativa em prática nas organizações burocráticas e nas substantivas? Qual é a base epistemológica que sustenta a ação administrativa dessas organizações? E, a partir dessa base epistemológica, que proposições podem ser feitas para a formação do gestor social para a prática da ação administrativa em organizações substantivas e em sistemas de coprodução do bem público? Essas questões permitem que agora se apresente o objetivo deste trabalho.

Este artigo tem como objetivo sistematizar uma base epistemológica para demonstrar que as organizações substantivas realizam seus propósitos por meio de uma ação administrativa própria, cujo escopo vai além daquela praticada nas organizações burocráticas. Por via de consequência, demonstrar ainda que a formação do gestor da ação administrativa das organizações substantivas e dos sistemas de coprodução do bem público exige conhecimentos dessa base epistemológica, tanto de seus aspectos instrumentais quanto substantivos.

Para concretizar esse objetivo, após esta (1) introdução, faz-se a sistematização da (2) base epistemológica e a identificação das principais categorias teóricas que sustentam os argumentos desenvolvidos ao longo do trabalho. A partir da base epistemológica e das categorias teóricas, discute-se o (3) conceito da ação administrativa no âmbito da organização substantiva e da organização burocrática. Seguem a discussão e a apresentação de (4) proposições gerais para a formação do gestor da ação administrativa das organizações substantivas e dos sistemas de coprodução do bem público. O trabalho se encerra com algumas (5) considerações finais e as (6) referências bibliográficas.

Na busca do objetivo, serão utilizados os estudos desenvolvidos por Guerreiro Ramos, principalmente a Teoria da Delimitação dos Sistemas Sociais (RAMOS, 1981), o Conceito de Ação Administrativa (RAMOS, 1983) e a Teoria sobre Modelos de Homem Parentético ou Reflexivo, Reativo e Operacional (RAMOS, 1984). Esse autor é a principal referência para o desenvolvimento deste trabalho porque as teorias por ele elaboradas contêm categorias e conceitos que se conjugam com os propósitos do artigo, assim como o fato de ser dele o conceito de organização substantiva $e$ de ação administrativa. Em que pese a importância do mencionado autor, o trabalho não se completa sem a participação de outros pensadores, entre os quais se destacam Voegelin (1978) e Arendt (2014), e também aqueles que serão nominados na oportunidade em que suas ideias e teorias passarem a integrar este texto. Nesse ponto, é importante destacar que existem diversas abordagens ontológicas e epistemológicas 
além daquela em uso neste trabalho, mas discuti-las ou compará-las não faz parte do objetivo que aqui se persegue. O que aqui se objetiva é sistematizar uma base epistemológica a partir dos argumentos desenvolvidos pelos autores que embasaram este trabalho. A sistematização dessa base epistemológica tem um caráter heurístico ou modelo ideal e de possibilidade objetiva, segundo a compreensão que Weber (2009) conferiu a esses dois conceitos.

Antes de dar seguimento a este trabalho, é importante lembrar que os conceitos de organização substantiva e ação administrativa já mereceram comentários em sua introdução, por isso mesmo e quando especificamente necessários serão eles retomados. No que se refere às possibilidades objetivas, Ramos (2014, p. 58.) afirma que

[...] são na verdade conjecturas, mas conjecturas cujo poder de convicção pode ser justificado por um conhecimento positivo e controlável dos acontecimentos; não refletem 'nossa ignorância ou conhecimento incompleto' dos fatos [...]. O conceito de possiblidade constitui, pois, um requisito essencial na análise científica da realidade social.

Quanto à epistemologia, ela é um metadiscurso que oferece suporte para a discussão científica (JAPIASSU, 1991).

Os próximos dois tópicos sistematizam a base epistemológica e as principais categorias teóricas segundo as quais as organizações substantivas realizam os seus propósitos por meio de uma ação administrativa própria que intenta suplantar aquela praticada nas organizações burocráticas.

\section{Base Epistemológica das Organizações Substantivas}

A tentativa de sistematizar uma base epistemológica para demonstrar que os propósitos das organizações substantivas são realizados por meio de uma ação administrativa própria deve começar por definir, embora de maneira abrangente, o que constitui e onde se situa essa base epistemológica, além de identificar a sua referência ontológica. Sobre a importância dessa referência ontológica, veja-se Voegelin (1978), Chia
(1997) e ainda Cunliffe e Jun, (2005) e Bevir (2013). É preciso se perguntar, então, qual é a base epistemológica das organizações substantivas? Que referência ontológica caracteriza essa base e em que ela se diferencia daquela que dá suporte às organizações burocráticas? Essa base epistemológica e seus fundamentos ontológicos serão elaborados no próximo tópico.

\subsection{Dimensões e Categorias da Base Epistemológica}

As organizações substantivas ancoram sua base epistemológica nas referências elaboradas por Voegelin (1978), Arendt (2014) e Ramos (1981). As referências elaboradas por esses autores ultrapassam as concepções imanentistas de realização humana no processo histórico, inspirando-se no pensamento clássico grego e na sua forma peculiar de representação e de compreensão da transcendência humana, a partir de um "paradigma meta-histórico" (RAMOS, 1981, p. 53). De acordo com Azevedo e Albernaz (2006), essa representação e compreensão supera o antropocentrismo que define o ser humano como centro de todo o entendimento de humanidade. Ademais, de acordo com Aristóteles (SKINNER, 1996), a sociedade é o ser humano em escala ampliada; ou seja, para que o ser humano possa exercer a sua humanidade, nela incluída a autorrealização, a sociedade precisa proporcionar-lhe um espaço para tal (ARENDT, 2014). Essa concepção meta-histórica e a ideia de harmonia e equilíbrio entre as dimensões e categorias que constituem o ser humano e o ordenamento da sociedade são a essência da base epistemológica de todos os arranjos humanos. Afinal, a sociedade não pode ser ordenada de forma a constranger a possibilidade de autorrealização humana. Passa, então, a ser um imperativo, para os propósitos deste trabalho, definir as dimensões e as categorias essenciais que constituem o ser humano $e$ os espaços que elas projetam na sociedade; uma vez que tais dimensões e categorias se tornam elementos que identificam a base epistemológica que se pretende sistematizar.

Para dar conta dessa tarefa, é preciso ter em mente que o ser humano é multidimensional, já que ele é, ao mesmo tempo, um ente político, social, comunitário e econômico, dotado, em sua psique, de uma força capaz de lhe ordenar a vida. Essa força é denominada 
razão (VOEGELIN, 1978; SNELL,1982). Assim, mercê da razão, o ser humano é capaz de fazer escolhas lúcidas, calculadas, instrumentais e identificar se as ações que decorrem dessas escolhas têm um caráter substantivo e de legitimidade. Weber (2009), Mannheim (1998) e Voegelin (1978) denominaram esse predicado da razão, respectivamente, de racionalidade instrumental ou funcional e racionalidade substancial ou noética. Alicerçado nesses autores, Ramos (1983, p. 38) afirma que

[...] atos ou elementos são funcionalmente racionais quando, articulados e relacionados com outros atos ou elementos, contribuem para que se logre atingir um objetivo predeterminado. É, pois, em função do objetivo preestabelecido que se afere esse tipo de racionalidade.

Ainda de acordo com Ramos (1983, p. 39), "[...] diz-se que é substancialmente racional todo ato intrinsecamente inteligente, que se baseia num conhecimento lúcido e autônomo de relações entre fatos". Completa o autor: "É um ato que atesta a transcendência do ser humano, sua qualidade de criatura dotada de razão". Esse complemento que o autor faz do conceito da racionalidade substantiva é muito importante porque define a relação que ele estabelece entre esse predicado da razão e a sua base ontológica, ou seja, a transcendência humana, consoante o entendimento que já foi atribuído a esse termo neste trabalho. A partir desse fundamento ontológico, a multidimensionalidade humana e a razão e seus predicados estão entre os elementos essenciais para sistematizar a base epistemológica por meio da qual se quer demonstrar que as organizações substantivas realizam os seus propósitos por meio de uma ação administrativa própria, cujo objetivo se propõe ir além daquela praticada nas organizações burocráticas.

O ser humano tem ainda a qualidade de ser único. Essa unicidade se expressa pelo uso da razão, tanto nos seus aspectos instrumentais quanto nos substantivos. O pressuposto maior para o uso da razão é a liberdade a que cada ser humano tem direito para poder fazer suas escolhas e avaliar a legitimidade das ações praticadas em função dessas escolhas (ARENDT, 2008). Essa condição de ser livre atribui ao ser humano responsabilidade única pelos atos que lucidamente pratica. Corolário desse primado são a ética da responsabilidade e a ética da convicção, que definem a responsabilidade e a legitimidade das ações praticadas em função das escolhas feitas (ARISTOTELES, 2001; WEBER, 2009). Assim, constituem-se como elementos essenciais da base epistemológica ora em construção: a multidimensionalidade humana - integrada pelas dimensões política, social, comunitária e econômica; a unicidade do ser humano e a razão - com o seu predicado substancial e instrumental; e a ética da convicção e da responsabilidade. Em momento próprio, ao longo deste trabalho, esses elementos farão parte da sistematização da base epistemológica que se pretende desenvolver.

As dimensões, a razão e a unicidade do ser humano também projetam tempos e espaços necessários à existência e à autorrealização humana, conforme já foi discutido neste trabalho. Entre esses tempos está o da reflexão mais íntima e da criatividade, também denominado de tempo de salto ou kairos, que ocorre em espaços pessoais ou de pequenos grupos. A noção de espaço aqui é empregada nos termos elaborados por Santos (1988). Também fazem parte da condição humana, o tempo convivial, que se realiza na prática da amizade e da justiça (ARENDT, 2008), e o tempo cronológico, que mede o caminhar e a duração da existência de cada ser humano. Os espaços da existência humana, além do estritamente pessoal também denominado de fenonomia, comportam ainda o espaço isonômico e o econômico. O isonômico é aquele que oferece a possibilidade de participação em condições de igualdade aos seus integrantes. Por outro lado, o espaço econômico é desigual, hierárquico e constrangedor da liberdade humana, porém necessário para a produção de bens e serviços. Usualmente o espaço econômico é o do mercado e o das burocracias, que são estratégias formais para a produção e a alocação de bens e serviços. Associado ao espaço pessoal está o tempo da reflexão ou do pensamento mais íntimo ao qual se refere Arendt (2008). O tempo convivial é associado ao espaço isonômico, comunitário, e o tempo cronológico à economia. Na fenonomia e na isonomia, o ser humano tem maior grau de liberdade; logo, tem a possibilidade de nelas agir sem maiores constrangimentos, ao passo que, na economia, o grau de liberdade é mais restrito (ARENDT, 2014). A economia e sua principal estratégia de produção, a burocracia, integram a esfera privada. Na economia $e$, consequentemente, na burocracia, impóe-se a 
dominação; é, portanto, da natureza desses espaços a prática do tolhimento da liberdade humana. Mas é importante destacar que cada um desses espaços é necessário à existência do ser humano $e$ inerente à condição humana. Cabe encontrar o equilíbrio entre o tempo dedicado a cada um desses espaços, de forma que cada ser humano tenha a possibilidade objetiva da autorrealização.

\subsection{Sistematização da Base Epistemológica}

A partir das considerações feitas até esse ponto, os elementos essenciais para a sistematização da base epistemológica ora em construção compreendem: a multidimensionalidade humana integrada pelas dimensões política, social, comunitária e econômica; a unicidade do ser humano; a razão, com o seu predicado substancial e instrumental; a ética da convicção e a da responsabilidade; o tempo pessoal, convivial e cronológico; o espaço pessoal da fenonomia, o isonômico e o econômico; o ser humano e a possibilidade de ser reflexivo, reativo e operacional - três categorias elaboradas por Ramos (1984) ao discutir os modelos de homem. Também fazem parte da base epistemológica os conceitos de ação, comportamento e autorrealização, embora este último seja um índice linguístico, segundo expressão elaborada por Voegelin (1978).

Cumpre, agora, correlacionar essas dimensões, categorias e conceitos de modo a sistematizar a base epistemológica por meio da qual se quer demonstrar que os propósitos das organizações substantivas se realizam por meio de uma ação administrativa própria, diferente daquela praticada nas organizações burocráticas.

A dimensão política, expressa no zoon politikon de Aristóteles (BARKER, 1995), é exercida pelo ser humano, por meio de sua participação em ambientes livres de maiores imposições que possam constranger a ação em benefício da comunidade e da coletividade. Esse entendimento da dimensão política repousa nos fundamentos ontológicos já apresentados neste trabalho. Dele decorre que o ser humano é unidimensionalizado sempre que se lhe tolhe a possibilidade de exercer a ação política em benefício da comunidade e da coletividade. Portanto, ambientes que tolhem a liberdade humana ou aqueles em que as regras são impostas de forma autocrática são deformadores da psique humana. Esses ambientes reificam o ser humano e o alienam da conscientização de si próprio (FREIRE, 2008). Logo, a possibilidade objetiva de autorrealização do ser humano é maior em organizações em que a imposição coercitiva de regras é menor e a participação no processo decisório sobre normas e procedimentos é maior. Sendo este o caso das organizações substantivas, como se verá na sequência deste trabalho, essa é uma importante referência da base epistemológica para demonstrar que as organizações substantivas realizam os seus propósitos por meio de uma ação administrativa própria que ultrapassa aquela praticada nas organizações burocráticas.

Essa condição de liberdade e de participação exige uma interface do espaço da economia com o da isonomia na produção de bens e serviços. Essa sobreposição permite que as pessoas, sob o jugo do trabalho controlado pelo tempo cronológico, possam viver momentos sob os benefícios da igualdade que é proporcionado pelo tempo convivial. Em organizações de alta base tecnológica, equipes autodirigidas têm a possibilidade de auferir os benefícios do tempo convivial. Também em organizações que promovem serviços de bem-estar para a comunidade, tais como, formação de grupos de estudo e reflexão, grupos de suporte a crianças e de entretenimento aos idosos, oferecem oportunidade do exercício do tempo convivial. As organizações que pertencem à economia de comunhão $e$ de prática da dádiva também podem ser referenciadas como exemplo da interface do espaço da economia e da isonomia (BRUNI, 2008; VIZEU, 2009). Portanto, organizações que impõem menor constrangimento sobre a ação do ser humano e permitem que nelas se exercite o tempo convivial são mais adequadas à autorrealização humana do que organizações em que apenas se mantém o tempo cronológico.

A condição de ser único torna o ser humano responsável pelos atos que lucidamente escolhe e pratica, tanto perante si mesmo quanto perante a comunidade a que pertence. O entendimento proposto por Aristóteles (2001) para a ética está ancorado no predicado da unicidade humana e na possibilidade da plenitude do exercício da razão em seus múltiplos aspectos. Considerando que o exercício da ética da convicção e da responsabilidade requer espaços isonômicos nos quais prepondera a liberdade e a participação de todos, faz sentido a luta permanente em prol da democracia 
e da maior participação no processo decisório nas organizações. Portanto, estruturas e tecnologias organizacionais que permitem ao ser humano exercer a ética da convicção e a ética da responsabilidade no arranjo organizacional de que é partícipe, são mais adequadas à multidimensionalidade humana $e$ à possibilidade de autorrealização. Também tornam mais complexas as tecnologias organizacionais, principalmente aquelas relacionadas com os processos, normas e comportamentos. Nessas estruturas e tecnologias organizacionais, a educação e a capacitação das pessoas que integram a organização adquirem uma nova feição, mais complexa e desafiadora, destacando-se aqui o preparo daqueles a quem cabe a gestão desses tipos de organização. Para os objetivos deste trabalho, essa constatação é importante, uma vez que está relacionada com a formação do gestor social.

Os espaços da fenonomia, da isonomia e da economia são todos necessários à existência humana, conforme já foi discutido neste trabalho. A fenonomia é um privilégio à liberdade humana; a isonomia, à convivialidade humana; e a economia, à produção de bens e serviços para satisfação das necessidades de sobrevivência do ser humano. Essas três categorias da base epistemológica que ora se elabora podem ser caracterizadas por meio do grau de liberdade que cada uma delas proporciona ao ser humano. O grau de liberdade ou de escolhas pessoais para o exercício das convicções, na fenonomia, é quase absoluto; na isonomia, está sob o domínio da ética da convicção, mas também da responsabilidade do ser humano como integrante de um grupo convivial; e, na economia, está condicionado pela responsabilidade no cumprimento da regra, da norma e dos comportamentos definidos e padronizados para o desempenho responsável do papel organizacional. Resta então a necessidade de se desenharem organizações que aprimorem a interface entre os predicados da fenonomia, da isonomia e da economia em que a regra, a norma e os comportamentos padronizados sejam voltados para resultados, mas que permitam ao ser humano exercer as suas convicções e responsabilidades consciente de sua condição humana.

Embora o ser humano parentético ou reflexivo seja mais requerido na fenonomia, o reativo, em ambientes sociais e conviviais e o operacional, nas economias, é simplista afirmar que o ser humano, como um ser único, possa se fazer presente parcialmente em cada um desses espaços da existência humana. O desafio, portanto, é conceber organizações em que o ser humano tenha a possibilidade objetiva de exercer a reflexão - pensar, reagir aos ditames da organização - e realizar seu trabalho operacional direcionado para a produção de bens e serviços. Grosso modo, essa utopia, amparada pela possibilidade objetiva, coloca o desafio de que sejam concebidas organizações em que as tecnologias organizacionais possam ser utilizadas com o grau de complexidade e sofisticação aqui sugerido. Esse também é o desafio que se põe à capacitação do gestor social, porquanto a sua formação requer os contornos que se atribui ao modelo de ser humano de natureza parentética ou reflexiva.

A sistematização da base epistemológica inclui os fundamentos ontológicos, as dimensões, as categorias, os conceitos e a autorrealização, como índice linguístico, discutidos ao longo deste tópico. Essa base parte do pressuposto de que a autorrealização é da essência do ser humano. Inclui, também, a assertiva de que normas e regras impostas de forma autocrática em espaços de natureza econômica e burocrática são deformadoras da psique humana, uma vez que elas alienam e reificam o ser humano $e$ tolhem a possibilidade de autorrealização. A base epistemológica também admite por certo que a participação das pessoas no processo decisório para definir normas e procedimentos nas organizações é necessária à autorrealização, porque a participação é uma expressão da multidimensionalidade humana. A noção de tempo nas organizações requer a inclusão do tempo pessoal ou de salto, assim como o tempo convivial, já que essas categorias auxiliam a superar a unidimensionalização, própria dos ambientes formais de natureza burocrática. A sistematização da base epistemológica também engloba a prática da ética da convicção nas organizações, de modo que as pessoas que dela participam assumam, de forma consciente, a responsabilidade pelos resultados que devem produzir nesses espaços. Para que isso venha a se dar, há necessidade de estruturas e tecnologias mais flexíveis, além de novas estratégias para a educação e a capacitação dos gestores das organizações. A base epistemológica ainda agrega a possibilidade de se criarem organizações em que haja interface dos espaços da fenonomia, da isonomia e da economia, condição que caracteriza a organização substantiva. Essa base epistemológica tam- 
bém inclui a possibilidade de as pessoas que integram as organizações praticarem a reflexão, o pensar, a convivialidade e a operosidade humana direcionada para a realização de resultados, neles incluída a possibilidade de autorrealização. Permite finalmente afirmar que a coprodução do bem público, mercê da interface entre a organização burocrática $e$ a organização substantiva, pode fomentar mudanças na estrutura, na tecnologia e nas teorias existentes no espaço e na cultura dessas organizações.

A sistematização das principais dimensões, categorias e conceitos sob forma de uma base epistemológica deve agora ser direcionada para demonstrar que as organizações substantivas realizam os seus propósitos por meio de uma ação administrativa própria, mais ampla do que aquela praticada nas organizações burocráticas.

\section{Conceito de Ação Administrativa nas Organizações Burocráticas e nas Organizações Substantivas}

O propósito que se desenvolve neste tópico requer a discussão dos conceitos de organização burocrática, organização substantiva e ação administrativa e, também, que se compare a ação administrativa que ocorre no âmbito da organização burocrática com a que se realiza na organização substantiva. Por meio dessa discussão e dessa comparação, demonstra-se que as organizações substantivas realizam uma ação administrativa própria, cuja intencionalidade ultrapassa aquela praticada nas organizações burocráticas.

\subsection{Conceito de Organização Burocrática}

A organização burocrática, como concebida por Weber (2009), retratada por Gerth e Mills (1999) e por Denhardt, Catlaw (2014), é um grupo social regido pela eficiência e competência, estabelecidas por meio de normas e regras impessoais, pela hierarquia, coordenação centralizada e a divisão do trabalho e pela dedicação ao trabalho controlado por meio do tempo cronológico e pelo desempenho de cargos subordinados a normas abstratas. As pessoas que integram o espaço organizacional estão sob o controle da cultura e da linguagem próprias da organização e são condi- cionadas permanentemente a realizar a produção de bens e serviços. Esse condicionamento está associado à razão da existência dessas organizações, ou seja, a produção de bens e serviços, não a autorrealização dos seus membros. De fato, dificilmente se encontrariam entre os objetivos do planejamento estratégico de qualquer organização burocrática a proposta de desenvolvimento e autorrealização das pessoas que trabalham nesse tipo de organização. Se essas organizações incorporassem esse objetivo, o entendimento da racionalidade e da ética aplicadas ao seu espaço precisaria ser ampliado, pois só o simples cálculo de consequências e a responsabilidade pela produção são insuficientes para tratar das questões do desenvolvimento e da autorrealização do ser humano. Essas são questões mais próximas da racionalidade substantiva $e$ da ética da convicção, conforme foi discutido na base epistemológica sistematizada neste trabalho.

Nas organizações burocráticas, a produção ocorre graças à tomada de decisão e à operacionalização dessas decisões. Nessas organizações, a produção está orientada, também, por normas de racionalidade e de responsabilidade, sendo peculiar desse espaço o tolhimento da liberdade e o cerceamento das escolhas pessoais. Portanto, a ação que ocorre dentro das organizações está sob o foco da dimensão instrumental da razão e da ética da responsabilidade que justificam os atos que nelas se praticam. A organização burocrática, embora seja considerada a melhor estratégia inventada pelo ser humano para a produção de bens e serviços, acarreta a unidimensionalização do ser humano (MARCUSE, 1979). Essa unidimensionalização também é o tema de Arendt (1983) e Kafka (2003) quando discutem duas personalidades, Eichmann e Josef K, que expressam, no primeiro caso, a deformação a que pode levar a racionalidade instrumental do etos burocrático e, no segundo caso, o absurdo extremo a que pode levar a prática da ética da responsabilidade. Aliás, as organizações burocráticas facilmente podem se tornar sistemas dominados pela irracionalidade que leva à degradação humana. Por isso mesmo, a irracionalidade também pode compor, em caso extremo, a ação administrativa. Eichmann, uma pessoa real, e Josef K, uma ficção criada por Kafka, bem atestam a afirmação que aqui se faz. Vale lembrar que as organizações burocráticas públicas, também denominadas organizações públicas, estão sujeitas às 
mesmas normas de racionalidade e irracionalidade das organizações burocráticas da esfera privada. Tal ocorrência mereceria maiores considerações, porém elas estão além dos propósitos estatuídos para este trabalho. Feitos esses comentários, cabe indagar por que as organizações geram esses resultados antagônicos e qual a relação desses resultados antagônicos com a prática da racionalidade e da ética no espaço das organizações. Esses questionamentos conduzem, agora, à discussão do conceito de organização substantiva e, a seguir, à elaboração do conceito de ação administrativa e identificação das principais categorias que constituem essa ação.

\subsection{O Conceito de Organização Substantiva}

As organizações substantivas pertencem à esfera pública, de acordo com o entendimento que Arendt (2014) empresta a esse termo; prestam serviços relevantes, sob o ponto de vista comunitário; têm características isonômicas e apresentam peculiaridade de gestão pelo tipo de ação administrativa que nela se pratica. Os objetivos das pessoas que delas participam são singulares, uma vez que elas usualmente não estão apenas motivadas pelo ganho econômico imediato, mas por motivos outros, entre os quais a possibilidade objetiva de autorrealização, atingível porque as organizações substantivas se regem ao abrigo da racionalidade instrumental e da substantiva, bem como da ética da responsabilidade e da convicção. Sob a orientação dessa concepção ampliada de racionalidade e de ética, o espaço da organização substantiva realiza os seus objetivos, entre os quais estão a prestação de serviços para a comunidade, o desenvolvimento pessoal e a possibilidade de autorrealização de seus participantes.

Esse espaço também se caracteriza pelo exercício do tempo cronológico e convivial, pela interação simbólica (REYNOLDS, HERMAN-KINNEY, 2003) e pela realização do trabalho como uma ocupação humana (ARENDT, 2014). É necessário chamar a atenção para o fato de que as organizações substantivas podem assumir os padrões das organizações burocráticas, em detrimento da sua substantividade, sempre que o seu tamanho tolher o contato face a face dos seus membros. Por outro lado, sempre que houver convergência da ação administrativa da organização substantiva e da organização burocrática pública para a coprodução do bem público, a gestão da organização substantiva e a administração da organização pública estão sujeitas, também, às normativas da racionalidade substantiva e da ética da convicção. Esse fato é relevante para a formação dos administradores públicos e gestores sociais que coordenam sistemas de coprodução do bem público.

A concepção que usualmente se faz de organização substantiva é a de um modelo heurístico, como o da organização burocrática. Embora essa questão já tenha sido discutida na introdução deste trabalho, pode ocorrer que, pela falta de conhecimentos sobre o conceito de tipo ideal, pessoas sejam levadas a questionar a possibilidade da existência de organizações substantivas. Essa, porém, é uma indagação ingênua e simplista, pois, no mundo concreto, só existe a possibilidade de tipos mistos, embora algumas características de um modelo possam ser preponderantes, como é o caso atual do modelo de mercado. É importante ter em mente que os tipos ideais são sempre referências e que a sua formulação teórica é fruto de uma construção abstrata (CARRIERI, PAÇO-CUNHA, 2009).

Por outro lado, se os arranjos associativos e comunitários da esfera pública pouco ainda se parecem com o tipo ideal da organização substantiva, mais importante, ainda, é estudá-las e preparar gestores públicos e sociais que sejam capazes de facilitar $e$ articular estratégias para transformar esses arranjos em organizações que mais se assemelhem ao tipo ideal de organização substantiva. Vale lembrar que essa transformação se faz sensível quando vista sob a perspectiva da autorrealização humana. Feitas essas considerações, segue a elaboração do conceito de ação administrativa, tanto na organização burocrática quanto na substantiva, e a identificação das principais categorias que constituem essa ação.

\subsection{O Conceito de Ação Administrativa}

A ação administrativa que ocorre no âmbito das organizações burocráticas é uma modalidade de ação social que se consagra pela prática da racionalidade instrumental e pela ética da responsabilidade direcionada para o alcance de objetivos. Para que se possa discutir a ação administrativa que se processa nas organizações, tanto as burocráticas quanto as substan- 
tivas, há necessidade de se identificarem as categorias que integram essa ação. Essas categorias, de acordo com Ramos (1983) são: motivação e produtividade no trabalho; interação entre ambiente e organização; alienação; poder; consentimento; superconformidade; reificação no espaço organizacional; racionalidade funcional e substancial; ética da responsabilidade e da convicção; tensão ética e dualidade de espaços da existência humana. Essas categorias da ação administrativa serão discutidas a seguir, de forma geral e muito breve. Tal discussão antepõe a ação administrativa no âmbito da organização burocrática à ação administrativa que ocorre no espaço da organização substantiva. Essa anteposição permitirá que se demonstre a peculiaridade da ação administrativa das organizações substantivas.

\subsection{Escopo da Ação Administrativa na Organização Burocrática e na Organização Substantiva}

A ação administrativa não se realiza em todas as organizações de forma idêntica e homogênea. Ela se reveste de nuances singulares, segundo o tipo de organização. Assim, em organizações mais participativas com algumas características substantivas, a ação administrativa se diferencia daquelas em que há maior coercitividade, alienação e reificação. As tipologias organizacionais e formas de consentimento apresentadas por Etzioni (1981) oferecem um referencial para a análise da ação administrativa nos diversos tipos organizacionais. Embora seja tentador examinar essas tipologias e a ação administrativa pertinente a cada uma delas, essa discussão está além do propósito que aqui se persegue. Aliás, essa discussão já foi explorada por Ramos (1983) quando analisou as tensões éticas na organização. Neste trabalho cabe tão somente antepor a prática da ação administrativa na organização burocrática à da organização substantiva. O propósito dessa comparação é demonstrar que a ação administrativa praticada na organização substantiva é mais abrangente do que a da organização burocrática.

Nas organizações burocráticas, a motivação das pessoas para a produção de bens e serviços é, usualmente, fruto de técnicas behavioristas. Essas técnicas, quando aplicadas de maneira continuada, tornam a maioria das pessoas submissas e sem iniciativa. A tentativa para superar essa submissão, que muitas vezes assume a forma de indolência e aversão ao trabalho, usualmente se faz por meio de métodos de controle burocrático e pela aplicação de outras técnicas de estímulo e reforço. A reincidência dessas técnicas e desses controles mais agrava do que resolve a situação (FRANKL, 2011). Habitualmente, o resultado final desse processo de unidimensionalização humana se manifesta na perda do emprego, ou em doenças psíquicas, ou na submissão total da pessoa ao espaço organizacional. Essa unidimensionalização do ser humano o reifica, coisifica, aliena e o torna superconforme aos ditames da organização, enfim, ela se manifesta na degradação humana e no absurdo, anomalias retratadas por Arendt (1983) e Kafka (2003) e já comentadas neste trabalho.

Já nas organizações substantivas, a motivação das pessoas é intrínseca ao objetivo da organização; está associada à ética da convicção e ao significado que se faz presente na interação simbólica (REYNOLDS; HERMAN-KINNEY, 2003); (MELTZER, 1980). Essa interação se sustenta na indagação do significado da existência e foi associada por Frankl (2011) ao sentido da própria vida. A partir dessa questão fulcral, a motivação deixa de ser apenas para o trabalho, esforço oneroso, e se volta para a ocupação que se caracteriza pelo esforço que se assume livremente por ser autogratificante. A propósito desses dois conceitos, Arendt (2014) associa ambos à condição humana, mas coloca como imperativo primeiro a ocupação, por estar relacionada à liberdade humana. Percebe-se, então, que a motivação das pessoas no espaço de produção das organizações substantivas sempre é complexa porque apresenta ingredientes associados à prática da liberdade, próprios das isonomias, e, outros, associados a comportamentos ditos da organização burocrática. A articulação entre ambas as organizações requer mais do que preparo para condicionar pessoas, técnica comumente ensinada nas escolas de administração. Ela requer a capacidade de articular a prática das isonomias com a das organizações burocráticas. Nesse caso fica evidente que a formação do gestor social requer conhecimentos que estão além daqueles necessários à capacitação do administrador de organizações burocráticas. Fica patente, também, que a ação administrativa envolvendo a motivação para a produção se diferencia em ambas as organizações, sendo mais singela na organização burocrática. 
O ambiente exerce influência sobre as organizações burocráticas; sabe-se, no entanto, até por meio dos manuais mais elementares de estratégia, que as organizações burocráticas também influenciam o ambiente. Nesse jogo estratégico, às organizações cabe controlar o meio para que possam sobreviver. À comunidade, parte do meio ambiente, cabe exercer o controle sobre as organizações burocráticas. Esse controle, denominado controle social é, apesar de seus críticos, essencial para a sobrevivência de uma sociedade democrática (COHEN, 1989). Por essa razão, o desenvolvimento de ações de responsabilidade social mostra-se estratégico na administração das organizações burocráticas (PINTO; MARANHÃO, 2009). Enquanto essas ações estiverem sob o domínio da racionalidade instrumental e da ética da responsabilidade, elas podem ser uma reação ao controle social da comunidade e não a convicção dos membros da organização sobre a importância de serem preservadas a comunidade e a democracia como bem maior da sociedade. Essa é uma disfunção da ação administrativa que pode se fazer presente nas organizações burocráticas, mas pouco visível no contexto da sociedade de massa (SANTOS, 2009).

Por outro lado, as organizações substantivas promovem a participação e o envolvimento da comunidade. Essa participação e envolvimento superam a necessidade do controle sobre a comunidade como se dá nas organizações burocráticas. Elas não têm na sobrevivência sua razão primeira, por isso podem transacionar com o meio ambiente sem os limites que a ação instrumental impõe às organizações burocráticas. A ação administrativa relacionada com o trato do meio ambiente praticada por essas duas organizações se diferencia porque a organização burocrática emprega a racionalidade instrumental e a ética da responsabilidade, ao passo que a organização substantiva se desenvolve, ainda, sob o signo da razão substantiva e da ética da convicção. Portanto, as relações com o ambiente também indicam que a ação administrativa das organizações substantivas tem uma prática diferenciada daquela utilizada pelas organizações burocráticas. É necessário incorporar a compreensão dessa prática diferenciada à formação do gestor social.

A motivação das pessoas que trabalham no espaço da organização burocrática, obtida por meio de técnicas de condicionamento, a impermeabilização das fronteiras organizacionais às influências do meio ambiente e o poder exercido no ambiente interno de maneira coercitiva ou utilitária degradam as pessoas e as alienam de si mesmas. Essa é a situação a que Freire (2008) se referia quando discutiu a conscientização humana ou quando Hegel cunhou o termo entfremdung que significa autoalienação (RAMOS, 1983). Assim, alienação, nos termos em que está sendo aqui empregada, refere a situação em que o ser humano perde a identidade própria ou quando passa a ser um estranho ou desconhecido para si próprio. Em ambientes organizacionais em que as pessoas participam por meio do consentimento, de escolha pessoal, como ocorre nas organizações substantivas, há condições de menor alienação e, consequentemente, possibilidade de maior envolvimento como forma de motivação. Essa pode ser uma das causas do comprometimento das pessoas em muitas organizações que prestam serviços para a comunidade. Constata-se, portanto, que as relações de poder e consentimento que ocorrem na ação administrativa praticada nas organizações substantivas se diferenciam daquelas utilizadas nas organizações burocráticas. Esse também é um fato importante a considerar na formação do gestor social.

O ser humano, nas organizações burocráticas, é levado a racionalizar permanentemente a sua conduta, de maneira a se submeter aos imperativos da produção. Essa racionalização pode conduzir as pessoas à alienação, à superconformidade e à reificação, além de eliminar a essência da interação simbólica. Nessa condição, o ser humano não pode mais viver a tensão entre a ética da responsabilidade e a da convicção, já não mais vive a condição humana, pois "se existe na história da humanidade alguma coisa constante, esta é a linguagem da tensão: entre vida e morte; entre ordem e desordem; entre os humores da alegria e do desespero; e entre a alienação, em seu duplo sentido de alienação do mundo e alienação de Deus" (VOEGELIN, 1975). Nas organizações substantivas, vive-se essa tensão, porque ela se faz presente na interação simbólica. Esse fato se deve, também, às características isonômicas e burocráticas presentes nesse tipo de organização, à prática da racionalidade substantiva e da funcional e à adoção da ética da responsabilidade e da convicção. As pessoas que nelas trabalham e se ocupam também vivem sob a tensão que decorre do confronto entre os ditames dessas duas perspectivas éticas. Por ser pertinente à condição humana, espera-se que os espaços da existência, princi- 
palmente os de produção de bens e serviços, permitam que o ser humano possa conviver com essa tensão, sem necessidade de praticar a racionalização ou a superconformidade à ética da responsabilidade. Pode-se afirmar que a ação administrativa que ocorre nos espaços da organização burocrática se diferencia, em muito, daquela que ocorre nas organizações substantivas, quando vista sob o prisma da necessidade da multiplicidade de espaços para o exercício da vida humana e a convivência com a tensão ética.

Essa discussão demonstrou que as organizações substantivas realizam uma ação administrativa própria, cujo objetivo ultrapassa aquela praticada nas organizações burocráticas. Em síntese, demonstrou-se que a ação administrativa que ocorre nas organizações substantivas se diferencia daquela das organizações burocráticas porque ela se rege pela racionalidade instrumental e substantiva, bem como pela ética da responsabilidade e da conviç̧ão. A ação, nas organizações substantivas, quase sempre está direcionada para prover o bem comum sob a forma de bens e serviços comunitários. Ela promove a interação simbólica e a prática da ocupação, além de conter em seu espaço, também, a liberdade própria das fenonomias $e$ isonomias. Esses fatores peculiares às organizações substantivas facilitam ao ser humano a autorrealização e ganhos que estão além de gratificações imediatas. Ela promove a convergência da racionalidade e da ética nos sistemas de coprodução para a produção do bem público. A formação do gestor social não pode deixar de levar em consideração essas peculiaridades da ação administrativa em prática nas organizações substantivas.

Indicados os principais pontos que diferenciam a ação administrativa praticada nas organizações substantivas daquela que ocorre nas organizações burocráticas, pode-se agora partir para a apresentação das proposições gerais sobre a formação do gestor social de organizações substantivas.

\section{Proposições Gerais para a Formação do Gestor Social de Organizações Substantivas}

A ação administrativa, na prática nas organizações substantivas, exige do seu gestor uma formação consentânea com a base epistemológica que a sustenta $e$ conhecimentos sobre as dimensões, categorias, conceitos e nuances que lhes são próprios e únicos. Apesar das mudanças que ocorrem na sociedade ocidental a partir da década de 60, a formação dos gestores sociais ainda não atinge, em profundidade e alcance, os conhecimentos que contém essa base epistemológica e os elementos da ação administrativa que conferem substantividade a essas organizações. Em que pese a mudança que vem ocorrendo, a formação do gestor social se dá, ainda e em muitos casos, pelo conhecimento dos métodos e técnicas gerenciais (BOULLOSA; SCHOMMER, 2009), quase sempre ao amparo da racionalidade instrumental e da ética da responsabilidade. Quando se trata da formação do gestor social, deve-se levar em conta, também, que a realidade das organizações substantivas, esteja ela mais ou menos próxima do modelo ideal que aqui se discutiu, está em constante mudança. Por isso, urge que o gestor social que está à frente dessas instituições tenha preparo para compreender os fenômenos ligados ao questionamento dos valores tradicionais da sociedade de mercado, aos constrangimentos à liberdade dos cidadãos, aos primados da ética, bem como aos limites da natureza ou biosfera.

Essas considerações sugerem que se infira da base epistemológica das organizações substantivas, mesmo considerada como modelo ideal, e dos elementos da ação administrativa em curso nessas organizações algumas proposições gerais para a formação do gestor social. Essas proposições gerais, no seu conjunto, não têm a pretensão de servir como programa de formação para gestores sociais; apresentam-se como referência voltada à discussão da formação do gestor social de organizações substantivas e de sistemas de coprodução do bem público. A síntese dessas proposições gerais, a seguir, será enunciada.

a) A formação do gestor social para atuar em organizações substantivas deve abranger os conhecimentos da base epistemológica e da ação administrativa próprias desse tipo de organização. Vale afirmar que essa formação deve se amparar nos campos da filosofia, ciência política, antropologia e sociologia, para citar apenas algumas áreas do conhecimento humano mais amplo, além, é evidente, do domínio das práticas instrumentais da ação administrativa. A formação do gestor social se estrutura, portanto, na multidisciplinaridade e na interdisciplinaridade. 
b) O gestor social deve ter conhecimentos acerca dos predicados da racionalidade substantiva e das implicações do emprego da ética da convicção, bem como das metodologias e tecnologias que lhe são próprias.

c) É relevante que o gestor social também tenha preparo e competência no emprego da racionalidade instrumental e da ética da responsabilidade, i.é, dos métodos e técnicas da gestão que ocorrem nas organizações burocráticas. Mas esse preparo e essa competência não se esgotam nesse tipo de racionalidade e de ética, conforme consta no item anterior.

d) A formação do gestor social precisa, ela própria, levar em conta a multidimensionalidade e a unicidade desse gestor, proporcionando-lhe a oportunidade de encontrar a autorrealização nessa formação. $\mathrm{O}$ desenho das tecnologias de ensino e de aprendizagem da gestão social precisa incorporar essa premissa ao processo de formação desse gestor.

e) As organizações substantivas, como conceituadas neste artigo, têm como principal função prover o bem comum à comunidade. Essa função de servir precisa ser incorporada à formação do gestor social, mesmo porque ele não dirige, coordena ou comanda a comunidade, ele a serve.

f) A interação simbólica e a prática da ocupação são essenciais à organização substantiva; por isso, a formação do gestor social requer a compreensão dessa interação e da ocupação como principal atividade de cada participante dessa organização. O significado e o sentido de vida, componentes da interação simbólica, são as fontes maiores da motivação daqueles que participam na organização substantiva, razão pela qual o gestor social precisa de formação especial para compreender essa fonte de motivação humana. Aliás, a formação continuada do gestor social também precisa estar impregnada por esse significado e esse sentido.

g) O gestor social, na sua prática cotidiana, é, também, um ser parentético, que exerce a reflexão. Daí a necessidade de prepará-lo para realizar essa atividade no espaço da organização substantiva.

h) A organização substantiva realiza as suas atividades por meio da participação das pessoas. O gestor dessas organizações precisa ter co- nhecimentos e desenvolver habilidades para articular a prática da participação das pessoas no espaço isonômico dessas organizações.

i) Como há muitas interfaces entre as organizações burocráticas públicas e as organizações substantivas para a coprodução do bem público, torna-se necessário que o gestor social as conheça e se capacite para coordenar sistemas de coprodução do bem público.

Esse conjunto de proposições gerais são algumas referências extraídas da base epistemológica que sustenta as organizações substantivas e da ação administrativa que se pratica nessas organizações. Elas servem para estimular a reflexão $e$ a criatividade daqueles que pretendem desenhar programas para a formação de gestores sociais. Cada proposição geral pode ser detalhada de maneira analítica para compor e integrar um programa específico para a formação de gestores sociais. Também serve como referência para orientar a prática da ação administrativa levada a cabo, diuturnamente, pelo gestor social. O próximo tópico faz algumas considerações finais, apresentadas como síntese deste trabalho.

\section{Considerações Finais}

Os objetivos deste trabalho englobaram a sistematização de uma base epistemológica para demonstrar que as organizações substantivas realizam seus propósitos por meio de uma ação administrativa própria, cujo escopo vai além daquela praticada nas organizações burocráticas. Destaca-se também que a formação do gestor social para a prática da ação administrativa em organizações substantivas requer conhecimentos dessa base epistemológica e dessa ação administrativa, principalmente quando essa ação está voltada para a coprodução do bem público.

Para concretizar esse objetivo, a base epistemológica foi sistematizada a partir de seus fundamentos ontológicos e pelas dimensões, categorias, conceitos $e$ índice linguístico que constituem o ser humano e a comunidade como sua extensão. Essa base epistemológica também serviu de referência para discutir e diferenciar a ação administrativa que ocorre nos espaços da organização burocrática e na organização substantiva. Essa diferenciação proporcionou alguns indicadores 
para a formulação de proposições gerais para a formação do gestor social. A base epistemológica, assim como as formulações sobre ação administrativa $e$ as proposições para a formação do gestor social foram construídas com sentido heurístico, portanto como modelo ideal que, quando levado à prática, corrompe-se em algum grau.

Cabe, ainda, um comentário final sobre o significado e a importância de se conhecer e levar em consideração uma base epistemológica para o estudo das organizações e da ação administrativa que nelas se pratica. Como exemplo deste trabalho, a base epistemológica é a âncora que sustenta todo o estudo da organização, ela é o fundamento das teorias e orienta o emprego das metodologias e tecnologias. Afinal, o estudo das organizações, que pertencem elas à esfera pública ou à esfera privada, sempre está eivado de uma verdade fundamental, seja qual for, da natureza simbólica, da existência social e da essência humana. Pode-se afirmar, como ocorreu ao longo deste trabalho, que a verdade fundamental que se assume é a orientação ontológica sobre a qual se constrói a base epistemológica. Portanto, os referenciais da base epistemológica impregnam o viés que se utiliza para estudar as organizações, independentemente de sua natureza. Este trabalho seguiu este caminho que sempre é muito abstrato e de reflexão; sem ele, porém, não seria possível levar a termo a discussão da ação administrativa no âmbito da organização substantiva e formular as proposições gerais para a formação do gestor dessas organizações.

\section{REFERÊNCIAS}

ARENDT, H. A condição humana. 11. ed. rev. Tradução Roberto Raposo, revisão técnica: Adriano Correia. Rio de Janeiro: Forense Universitária, 2014.

A Promessa da Política. Rio de Janeiro: Editora Bertrand Brasil Ltda., 2008.

Eichmann em Jerusalém: um relato sobre a banalidade do mal. São Paulo: Diagrama \& Texto, 1983.

ARISTÓTELES. Ética a Nicômaco. São Paulo: Martin Claret, 2001.
The Politics. Oxford (England): Oxford

University Press, 1980.

\section{AZEVÊDO, A.; ALBERNAZ, R. Alberto Guerreiro}

Ramos's Anthropological Approach to the Social Sciences: the parenthetical man. Administrative Theory \& Práxis, Washington, v. 28, n. 4, p. 501-521, dec. 2006.

BARKER, E. The Politics of Aristotle. New York: Oxford University Press, 1995.

BEVIR, M. Legitimacy and the Administrative State: Ontology, History, and Democracy. Public

Administration Quarterly, Elizabethtown, v. 37, n. 4, p. 535-549, winter, 2013.

BOULLOSA, R. F.; SCHOMMER, P. C. Gestão Social: caso de inovação em políticas públicas ou mais um enigma de Lampedusa? In: III ENAPEGS, Juazeiro $e$ Petrolina, 2009. Anais... Juazeiro e Pétrolina, 2009.

BOVAIRD, T. Beyond Engagement and Participation: User and Community Coproduction of Public Services. Public Administration Review, [S.l.], v. 67, n. 5, p. 846-860, sept.-oct. 2007.

BRUNI, L. Reciprocity, Altruism and Civil Society. London: Routledge \& Kegan Paul, 2008.

CALEGARE, M. G. A.; SILVA JUNIOR, N. A "construção" do terceiro setor no Brasil: da questão social à organizacional. Revista Psicologia Política, São Paulo, v. 9, n. 17, jun. 2009.

CANSADO, A. C.; SAUSEN, J. O.; VILLELA, L. E. Gestão Social versus gestão estratégica. In: TENÓRIO, F. G. (Org.) Gestão Social e Gestão Estratégica, experiências em desenvolvimento territorial. Rio de Janeiro: Editora FGV, 2013.

CARRIERI, A. P.; PAÇO-CUNHA, E. Notas Provisórias sobre o Desenvolvimento e a Superação dos Estudos Organizacionais. In: XXXI ENANPAD, Rio de Janeiro, 2009. Anais... Rio de Janeiro, 2009. (CD-ROM)

CATLAW, T. J. Fabricating the People: Politics and Administration in the Biopolitical State. Tuscaloosa: The University of Alabama Press, 2007. 
CHIA, Robert. Essays: Thirty Years on: from organizational structures to the organizational of thought. Organization Studies, Colchester, U.K, v. 18, n. 4, p. 685-707, 1997.

COHEN, S. The Critical Discourse on Social Control: notes on the concept as a hammer. International Journal of the Sociology of Law, [S. 1.], v. 17, n. 3, p. 347-357, aug. 1989.

CUNLIFFE, L.; JUN, J. S. The need for reflexivity in public administration. Administration \& Society, [S. 1.], v. 37, n. 2, p. 225-242, may, 2005.

DAHL, R. A. Poliarquia, participação e oposição. São Paulo: Editora da Universidade de São Paulo, 2005.

DENHARDT, R.; CATLAW, T. Theories of public organization. [S.l.]: Cengage Learning, 2014.

DENHARDT, Robert B. DENHARDT, Jane V. The New Public Service: serving, not Steering. 3. ed. New York: M.E. Sharpe, 2012.

DICKINSON, H.; SULLIVAN, H. Towards a General Theory of Collaborative Performance: The Importance of Efficacy and Agency. Public Administration, [S.l.], v. 92, n. 1, p. 161-177, mar. 2014.

ETZIONI, A. Organizações complexas: um estudo das organizações em face dos problemas sociais. São Paulo: Atlas, 1981.

FRANKL, V. E. Em Busca de Sentido. São Leopoldo: Sinodal, 2011.

FREIRE, P. Conscientização: teoria e prática da liberação. São Paulo: Centauro, 2008.

GERTH H.H.; MILLS C. W. From Max Weber: essays on sociology. New York: Oxford University Press, 1999.

JAPIASSU, H. Introdução ao pensamento

epistemológico. 6. ed. São Paulo: Francisco Alves, 1991.

KAFKA, F. O Processo. Rio de Janeiro: Globo, 2003.

KUHN, T. A Estrutura das Revoluções Científicas. São Paulo: Perspectiva 2005.
LEITÃO, S. P. GESUALDI Jr. L. C. Conhecimento, ensino da administração e mudança transformadora: uma visão crítica. Cadernos EBAPE, [S.l.], v. 4, n. 2, jun. 2006.

\section{MANNHEIM, K. Man and Society in an Age of}

Reconstruction. New York: Routledge \& Kegan Paul, 1998.

MARCUSE, H. A Ideologia da sociedade industrial. Rio de Janeiro: Zahar, 1979.

\section{MATIAS-PEREIRA, J. Governança no setor público.}

São Paulo: Editora Atlas, 2010.

\section{MELTZER, B.; PETRAS, J.; REYNOLDS, L. Symbolic}

Interactionism: Genesis, Varieties and criticism. London: Routledge \& Kegan Paul, 1980.

PINTO, M. R.; MARANHÃO, C. M. S. A.

Responsabilidade Social Empresarial: Reflexões á Luz dos Estudos Críticos em Administração. In: XI COLÓQUIO INTERNACIONAL DE PODER LOCAL, Salvador, 2009. Anais... Salvador, 2009. (CD-ROM)

RAMOS, A. G. A Nova ciência das organizações. Rio de Janeiro: Editora FGV, 1981.

Modelos de homem e teoria administrativa.

Revista de Administração Pública, Rio de Janeiro, v. 18, n. 2, p. 3-12, abr.-jun. 1984.

Administração e contexto brasileiro: esboço de uma teoria geral da administração. Rio de janeiro: Fundação Getúlio Vargas, 1983.

. A modernização em nova perspectiva: em busca do modelo da possibilidade. In: HEIDEMANN, F. G.; SALM, J. F. Políticas públicas e desenvolvimento: bases epistemológicas e modelos de análise. Brasília, DF: Editora da Universidade de Brasília, 2014. p. 51-89.

REYNOLDS, L.; HERMAN-KINNEY, N. (Ed.). Handbook of symbolic interactionism. [S.l.]: Rowman Altamira, 2003.

SALM, J. F. Coprodução de bens e serviços públicos. In: BOULlOSA, Rosana de Freitas (Org.). Dicionário para a formação em gestão social. Salvador: CIAGS/UFBA, 2014. p. 42-44. 
SALM, J. F; MENEGASSO, M. E. Os Pressupostos para a Implementação do Novo Serviço Público e o Capital Social. In: XI COLÓQUIO INTERNACIONAL DE PODER LOCAL. Salvador, 2009. Anais... Salvado, 2009. (CD$\mathrm{ROM})$

SANTOS, M. O Espaço em Questão. São Paulo: Editora Marco Zero Ltda., 1988.

SANTOS, A. L. N. Brasil: novas Agendas Sociopolíticas por Novos Pactos Sociais ainda Instáveis. Estabilidades Futuras Serão Possíveis? Cadernos de Gestão Social, [S.l.], v. 2, p. 175-183, set.-dez. 2009.

SERVA, Maurício. A racionalidade substantiva demonstrada na prática administrativa. Revista de Administração de Empresas, São Paulo, v. 37, n. 2, abr.-jun. 1997.

SKINNER, Q. As Fundações do Pensamento Político

Moderno. São Paulo: Companhia das Letras, 1996.

SNELL, B. The Discovery of the Mind. New York: Dover Publications, Inc., 1982.

VIZEU, F. Contribuições da Sociologia da Dádiva aos Estudos sobre Organizações Substantivas. Organizações \& Sociedades, Salvador, v. 16, n. 50, p. 409-427, jul.set. 2009.

VOEGELIN, E. Anamnesis. Notre Dame: University of Notre Dame, 1978.

From Enlightment to Revolution. Durham:

Duke University Press, 1975. Industrial Society in Search of Reason. In: ARON,

R. (Ed.) World technology and human destiny. Ann Harbor: University of Michigan Press, 1963.

WEBER, M. Economia e Sociedade. Brasília, DF: Editora da UNB, 2009. 